$1-1-2018$

\title{
Urinary retention in unilateral total knee arthroplasty: Comparison between continuous epidural analgesia and single-shot femoral nerve block
}

Ausaf Ahmed Khan

Aga Khan University, ausaf.khan@aku.edu

Robyna Irshad Khan

Aga Khan University, robyna.khan@aku.edu

Follow this and additional works at: https://ecommons.aku.edu/pakistan_fhs_mc_anaesth

Part of the Anesthesia and Analgesia Commons, and the Anesthesiology Commons

\section{Recommended Citation}

Khan, A. A., Khan, R. I. (2018). Urinary retention in unilateral total knee arthroplasty: Comparison between continuous epidural analgesia and single-shot femoral nerve block. Journal of the College of Physicians and Surgeons--Pakistan : JCPSP, 28(1), 5-8.

Available at: https://ecommons.aku.edu/pakistan_fhs_mc_anaesth/323 


\title{
Urinary Retention in Unilateral Total Knee Arthroplasty: Comparison between Continuous Epidural Analgesia and Single-Shot Femoral Nerve Block
}

\author{
Ausaf Ahmed Khan and Robyna Irshad Khan
}

\begin{abstract}
Objective: To compare the frequency of urinary retention and requirement of bladder catheterization in patients undergoing total knee arthroplasty while receiving either continuous epidural analgesia or single-shot femoral nerve block. Study Design: Randomized controlled study.

Place and Duration of Study: Operating Rooms of Aga Khan University Hospital, Karachi, from January 2014 to January 2015.

Methodology: Patients were randomized in two groups of 30 each, i.e. epidural group (group E) or femoral nerve block group (group F). Baseline parameters were recorded. Postoperatively, patients were followed for upto 24 hours to collect the data regarding urinary retention. Final outcome was taken at 24 hours postoperatively. Data was analyzed to compare the frequency of urinary retention between the two groups.

Results: The average age of the patients was $59.58 \pm 5.85$ years. There were $28(46.7 \%)$ male and $32(53.3 \%)$ female patients. Frequency of urinary retention was significantly high in Group $E$ than Group F (46.7\% vs. 6.7\%; $p=0.0005)$.

Conclusion: Single-shot femoral nerve block offers a more favorable profile in terms of postoperative urinary retention when compared to continuous epidural analgesia.
\end{abstract}

Key Words: Total knee arthroplasty. Femoral nerve block. Epidural analgesia. Urinary retention. Lumbar epidural anesthesia.

\section{INTRODUCTION}

Acute urinary retention is a common complication following lower limb arthroplasty with the incidence ranging from $10.7 \%$ to $84 \% .{ }^{1}$ Postoperative urinary retention can lead to significant morbidity, such as prosthetic infection and sepsis. ${ }^{2}$ The spread of infection from the urinary tract to cause deep joint sepsis has been well documented and is more common following knee arthroplasty with a quoted incidence of $2.5 \%$ as compared with $0.64 \%$ post-hip arthroplasty. ${ }^{1}$ Studies have shown increased incidence of urinary retention in patients using epidural when compared with nonepidural techniques. ${ }^{3-5}$ The incidence of postoperative urinary retention is significantly lower in patients receiving continuous peripheral nerve blocks compared with epidural anesthesia.6-8 However, in any of these studies urinary retention has not been looked as the primary outcome.

Pain after total knee arthroplasty (TKA) is severe,9,10 and effective postoperative pain control allows for earlier ambulation and initiation of physiotherapy, which hastens recovery, reduces the length of stay in the hospital, and lowers the risk of postoperative complications.

Department of Anaesthesiology, The Aga Khan University Hospital, Karachi.

Correspondence: Dr. Ausaf Ahmed Khan, Department of Anaesthesiology, The Aga Khan University Hospital, Karachi. E-mail:ausaf.khan@aku.edu

Received: July 07, 2017; Accepted: November 30, 2017.
This study is aimed to compare the frequency of urinary retention and requirement of bladder catheterization in patients undergoing TKA while receiving either continuous epidural analgesia or single-shot femoral nerve block; and also compared the frequency of postoperative nausea, vomiting and sedation, as well as surgical outcomes and patient satisfaction between the two groups.

\section{METHODOLOGY}

This randomized controlled study was conducted in the operating rooms of the Aga Khan University Hospital after approval from University's Ethics Review Committee (reference number: 2768). Primary investigator obtained written and informed consent from all ASA I, II \& III patients of either gender aged between 30 and 70 years, scheduled for unilateral total knee arthroplasty. Exclusion criteria were patient refusal, allergy to local anesthetics, paracetamol or other study drugs, history of opioid dependence, contraindications to spinal/epidural anesthesia, femoral nerve block (coagulation defects, infection at puncture site etc.), inability to use patientcontrolled analgesia (as assessed at the time of informed consent), history of urinary retention, neurogenic bladder, or any urologic problem. Patients were randomly allocated by draw method to either of the two treatment groups, i.e. epidural group (group E) or femoral nerve block group (group F). After application of routine monitoring, i.e. electrocardiography (ECG), pulse oximetry $\left(\mathrm{SpO}_{2}\right)$, non-invasive blood pressure (NIBP) 
and end-tidal carbon dioxide $\left(\mathrm{ETCO}_{2}\right)$, patients were induced using propofol $2 \mathrm{mg} / \mathrm{kg}$ and atracurium $0.5 \mathrm{mg} / \mathrm{kg}$; and endotracheal intubation was done. Anesthesia was maintained using isoflorane with oxygen and nitrous oxide, to maintain a MAC of 1 .

After induction of general anesthesia, patients were treated according to their group allocation. Patients in epidural group (group E) were turned to lateral position for epidural catheter placement in lumbar region. Epidural catheter was loaded with $0.25 \%$ bupivacaine and infusion of bupivacaine $0.1 \%+$ fentanyl $2 \mathrm{mcg} / \mathrm{ml}$ was started at $8-12 \mathrm{ml}$ per hour.

For patients in the femoral nerve block group (group F), ultrasound-guided femoral nerve block was performed using $20 \mathrm{ml}$ 0.375\% bupivacaine.

The surgeons were then allowed to proceed with the surgical procedure. After the completion of the procedure, patients were shifted to the Post-Anesthesia Care Unit (PACU). Time of arrival in the PACU was taken as 0-hour. Patient controlled intravenous analgesia (PCIA) was started for the patients in group $\mathrm{F}$; using morphine with a bolus of 1 to $1.5 \mathrm{mg}$, no background infusion, and a lock-out time interval of 10 minutes. Patients in both groups were prescribed inj. paracetamol 1-gm every 8 hourly till the time proper oral intake is started, when paracetamol was given $1 \mathrm{gm}$ every 8 hours, orally. If there was failure to perform epidural or nerve block, or the epidural was not working, then the patient was excluded from the study. Data regarding urinary retention was collected on the questionnaire at intervals 0 to 24 hours and final outcome for urinary retention was taken at 24 hours.

Sample size calculation was based on the study by Singelyn et al., where urinary retention was significantly higher in continuous epidural analgesia group than single shot femoral group (40 vs. 0\%). Therefore, P1 was considered as $40 \%$ and $P=0 \%$. A sample size of 16 patients per group would have a $95 \%$ power of detecting a $40 \%$ difference in frequency of urinary retention at the 0.05 level of significance. It was decided to include 60 patients (30 in each group) to account for possible dropouts.

Data was analyzed with SPSS (statistical package for social sciences) version 19. Frequencies and percentages were computed for qualitative variables like gender, urinary retention, postoperative nausea and vomiting (PONV) and sedation. Mean and standard deviation were computed for age, height and weight, maximal knee flexion, hospital stay, time taken to mobilize out of bed, and time of first solid meal intake. Independent sample t-test was applied to compare mean difference between groups and Chi-square test was used to compare frequency of urinary retention between groups. $p \leq 0.05$ was considered level of significance.

\section{RESULTS}

A total of 60 patients with unilateral total knee arthroplasty were included in the study. Patients were randomly allocated into two groups. Thirty patients were treated with epidural (Group E) and 30 were treated with femoral nerve block (Group F). The average age of the patients was $59.58 \pm 5.85$ years. Mean age, weight and height were not significantly different between the groups (Table I). There were $28(46.7 \%)$ male and 32 $(53.3 \%)$ female patients. Proportion of gender was also not significant between the two groups $(p=0.12)$ as presented in Table I.

Frequency of urinary retention in patients was not significant between groups at 0 hour and at 1 -hour but it was observed that at 12 hours urinary retention was significantly high in Group $\mathrm{E}$ as compared to Group $\mathrm{F}$ $(56.7 \%$ vs. $26.7 \%$; $p=0.018)$. Final outcome regarding the urinary retention of the patients between groups were assessed at 24 hours as also displayed in Table II. Frequency of urinary retention was significantly higher at 24 hours in Group E than Group F (46.7\% vs. 6.7\%; $\mathrm{p}=0.0005)$.

PONV scores were significantly low $(p<0.05)$ in Group F vs. Group E as shown in Table III. Sedation score and maximal knee flexion at 24 and 48 hours were not significantly different between groups. Mean hospital stay was significantly lower in group $\mathrm{F}$ as compared to group $E[157 \pm 9.75$ hours vs. $162.7 \pm 11.77$ hours; $p=0.046]$. Mean time taken to mobilize out of bed, was

\begin{tabular}{l|c|c|c}
\multicolumn{3}{l|}{ Table I: Comparison of characteristics of patients between groups. } \\
\hline Variables & $\begin{array}{c}\text { Group E } \\
\mathrm{n}=30\end{array}$ & $\begin{array}{c}\text { Group F } \\
\mathrm{n}=30\end{array}$ & P-value \\
\hline Age (years) & $58.97 \pm 6.01$ & $60.20 \pm 5.52$ & 0.42 \\
\hline Height $(\mathrm{cm})$ & $163.13 \pm 8.59$ & $164.83 \pm 8.97$ & 0.45 \\
\hline Weight $(\mathrm{kg})$ & $77.57 \pm 8.09$ & $80.03 \pm 8.29$ & 0.24 \\
\hline Gender, $\mathrm{n}(\%)$ & $11(36.7 \%)$ & $17(56.7 \%)$ & 0.12 \\
Male & $19(63.3 \%)$ & $13(43.2 \%)$ & \\
Female & $11(36.7 \%)$ & $15(50 \%)$ & 0.29 \\
\hline Procedure, $\mathrm{n}(\%)$ & $19(63.3 \%)$ & $15(50 \%)$ & \\
Left TKA & & & \\
Right TKA &
\end{tabular}

Data are presented as mean $\pm S D$ and $n(\%)$.

T-test for mean difference; Chi-Square test for proportion difference.

Table II: Compare the frequency of urinary retention in patients undergoing unilateral Total Knee Arthroplasty receiving continuous epidural analgesia vs. single-shot femoral nerve block.

\begin{tabular}{l|c|c|c}
\hline \multirow{2}{*}{ Time (hours) } & \multicolumn{2}{|c|}{$\begin{array}{c}\text { Urinary retention and need } \\
\text { of bladder catheterization }\end{array}$} & \multirow{2}{*}{ P-value } \\
\cline { 2 - 3 } & Group E & Group F & \\
\hline 0 hour & $\mathrm{n}=30$ & $\mathrm{n}=30$ & \\
\hline 1 hour & $28(93.3 \%)$ & $26(86.7 \%)$ & 0.38 \\
\hline 12 hours & $18(60 \%)$ & $17(56.7 \%)$ & 0.79 \\
\hline 24 Hours & $17(56.7 \%)$ & $8(26.7 \%)$ & $0.018^{*}$ \\
\hline (Final outcome) & $14(46.7 \%)$ & $2(6.7 \%)$ & $0.0005^{*}$ \\
\hline Chi-square test for proportion difference at each point time &
\end{tabular}

Chi-square test for proportion difference at each point time. 
Table III: Comparison of PONV between groups.

\begin{tabular}{l|l|c|c|c}
\hline Time & $\begin{array}{l}\text { Nausea and } \\
\text { vomiting scale }\end{array}$ & $\begin{array}{c}\text { Group E } \\
\mathrm{n}=30\end{array}$ & $\begin{array}{c}\text { Group F } \\
\mathrm{n}=30\end{array}$ & P-values \\
\hline Baseline & Zero - none & $18(60 \%)$ & $30(100 \%)$ & \\
& 1 - mild & $7(23.3 \%)$ & $0(0 \%)$ & \\
& $2-$ moderate & $5(16.7 \%)$ & $0(0 \%)$ & 0.001 \\
\hline 1 hour & Zero - none & $21(70 \%)$ & $18(60 \%)$ & \\
& 1 - mild & $9(30 \%)$ & $7(23.3 \%)$ & 0.065 \\
& $2-$ moderate & $0(0 \%)$ & $5(16.7 \%)$ & \\
\hline 2 hours & Zero - none & $22(73.3 \%)$ & $18(60 \%)$ & \\
& 1 - mild & $6(20 \%)$ & $10(33.3 \%)$ & 0.49 \\
& $2-$ moderate & $2(6.7 \%)$ & $2(6.7 \%)$ & \\
\hline 24 hours & Zero - none & $18(60 \%)$ & $30(100 \%)$ & 0.001 \\
& 1 - mild & $10(33.3)$ & $0(0 \%)$ & \\
& $2-$ moderate & $2(6.7 \%)$ & $0(0 \%)$ & \\
\hline 48 hours & Zero - none & $24(80 \%)$ & $30(100 \%)$ & \multirow{2}{*}{0.024} \\
& 1 - mild & $6(20 \%)$ & $0(0 \%)$ & \\
\hline
\end{tabular}

Chi-Square and Fisher exact test applied.

significantly low in group $F$ than group $E[25.73 \pm 4.18$ hours vs. $38.17 \pm 6.53$ hours; $p=0.0005$ ] while mean time of the first solid intake was not significant between groups [Group E vs. F: $9.23 \pm 2.92$ hours vs. $8.57 \pm 1.94 ; p=0.302$ ]. Regarding the satisfaction and recommendation of methods of pain relief, $83.3 \%(25 / 30)$ and $86.7 \%(26 / 30)$ patients were satisfied and $83.3 \%(25 / 30)$ and $93.3 \%$ $(28 / 30)$ responded to recommend the same method of pain relief to their family and friends in group $E$ and $F$, respectively. There were no significant differences between groups in rate of satisfaction and recommendation $(p=0.718$ and $p=0.228$ respectively).

\section{DISCUSSION}

Postoperative urinary retention remains a challenge and a topic of interest for arthroplasty, contributing to significant morbidity and can be the cause of prosthetic infection and sepsis as a consequence of hematogenic spread of infection secondary to bladder catheterization. The sequelae of postoperative urinary retention hinder mobilization and thus can increase the length of hospital stay. Considerable work has been done to estimate the incidence of postoperative urinary retention in joint arthroplasties. However, the available data regarding the incidence of postoperative urinary retention varies because of differences in the study designs and different criteria used to detect postoperative urinary retention as shown by Bjerregaard et al.11 The findings of this study are consistent with a higher frequency of postoperative urinary retention at 24 hours in patients receiving epidural analgesia (group E) when compared with femoral nerve block (group F). These results are consistent with the findings of a meta-analysis by Fowler et al.12 It showed a reduction in postoperative urinary retention with the use of peripheral nerve blocks. Similar results were shown in systemic reviews by Choi et al. ${ }^{13}$ and Cook et al.14 Balderi and Carli also reported comparable incidence of postoperative urinary retention in patients receiving peripheral nerve block in lower limb arthroplasty. ${ }^{15}$ In their retrospective review of 125 patients, Lingaraj et al. showed that use of postoperative epidural analgesia is associated with significant postoperative urinary retention. ${ }^{3}$ The study by McQueen et al. revealed a significantly increased incidence of urinary retention when comparing epidural with nonepidural anaesthesia.16 Singelyn et al. demonstrated that continuous femoral nerve sheath block has favorable side effect profile in comparison to epidural analgesia and intravenous patient controlled analgesia with morphine. 17

As stated earlier, literature reports a variable incidence of postoperative urinary retention owing to the difference in the definitions of outcome, i.e. postoperative urinary retention and also there is variance in study designs. Cochrane review by Chan et al. showed that there is no significant difference in the risk of urinary retention when comparing femoral nerve block with epidural, while looking at final outcome at 72 hours. ${ }^{18} \mathrm{Chu}$ et al. and Izard et al. did not show any difference between regional and general anaesthesia when comparing urinary retention. ${ }^{19,20}$ In a retrospective review, Kumar et al. showed increased postoperative urinary retention associated with postoperative morphine consumption. ${ }^{1}$ Chan et al. reported no significant difference in sedation scores, knee flexion at 24 hours, and time to first mobilize out of bed. ${ }^{18}$ They showed a reduced risk of nausea/vomiting and a higher patient satisfaction with femoral nerve block when compared to epidural analgesia. However, this Cochrane review included only 10 papers out of 45 , comparing epidural with femoral nerve block. It also concluded that continuous femoral nerve block is better than single-shot method.

The present study results are comparable to many of the previous studies; however, there are certain limitations to the generalization of results as the present study mainly focused on unilateral TKA. This study excluded pre-existing bladder outflow obstruction in patients that can confound the results and can be addressed using the International Prostate Symptom Score (IPSS) including patients with pre-existing bladder outflow obstruction in future carefully designed studies. The format of this study did not make it feasible to blinding, which confers a significant risk of bias. A study design that eliminates the risk of bias needs to be considered before the results can be considered generally applicable. Studies can be designed in the future to encompass a greater population of patients with varied procedures feasible for consideration of epidural analgesia vs. femoral nerve block that will better establish the findings of this study.

\section{CONCLUSION}

Single-shot femoral nerve block offers a more favorable profile in terms of postoperative urinary retention 
avoiding potential complications of urinary sepsis and prosthetic infection, thereby facilitating earlier mobilization and shorter in-hospital stay when compared to epidural analgesia. A recommendation for the change in analgesic modality can be considered after addressing the potential confounders and designing studies that establish these findings more strongly.

Acknowledgement: We like to thank Mr. Amir Raza for assistance with the protocol design and data management.

\section{REFERENCES}

1. Kumar P, Mannan K, Chowdhury AM, Kong KC, Pati J. Urinary retention and the role of indwelling catheterization following total knee arthroplasty. Int Braz J Urol 2006; 32:31-4.

2. Fernandez MA, Karthikeyan S, Wyse M, Foguet P. The incidence of postoperative urinary retention in patients undergoing elective hip and knee arthroplasty. Ann R Coll Surg Engl 2014; 96:462-5.

3. Lingaraj K, Ruben M, Chan YH, Das SD. Identification of risk factors for urinary retention following total knee arthroplasty: a Singapore hospital experience. Singapore Med J 2007; 48:213.

4. Lu Y, Huang HM, Yan J, Jiang H. Comparison of postoperative femoral nerve block, epidural block and intravenous patientcontrolled analgesia in pain control and postoperative rehabilitation after total knee arthroplasty. Int J Clin Exp Med 2017; 10:6680-7.

5. Moucha CS, Weiser MC, Levin EJ. Current strategies in anesthesia and analgesia for total knee arthroplasty. J Am Acad Orthop Surg 2016; 24:60-73.

6. Campbell A, McCormick M, McKinlay K, Scott NB. Epidural vs. lumbar plexus infusions following total knee arthroplasty: randomized controlled trial. Eur J Anaesthesiol 2008; 25:502-7.

7. Capdevila X, Barthelet Y, Biboulet P, Ryckwaert Y, Rubenovitch J, d'Athis F. Effects of perioperative analgesic technique on the surgical outcome and duration of rehabilitation after major knee surgery. J Am Soc Anesthesiol 1999; 91:8-15.

8. Singelyn FJ, Deyaert M, Joris D, Pendeville E, Gouverneur JM. Effects of intravenous patient-controlled analgesia with morphine, continuous epidural analgesia, and continuous three-in-one block on postoperative pain and knee rehabilitation after unilateral total knee arthroplasty. Anesth Analg 1998; 87:88-92.
9. Gerrard AD, Brooks B, Asaad P, Hajibandeh S, Hajibandeh S. Meta-analysis of epidural analgesia versus peripheral nerve blockade after total knee joint replacement. Eur J Orthop Surg Traumatol 2017; 27:61-72.

10. Fan L, Yu X, Zan P, Liu J, Ji T, Li G. Comparison of local infiltration analgesia with femoral nerve block for total knee arthroplasty: a prospective, randomized clinical trial. J Arthroplasty 2016; 31:1361-5.

11. Bjerregaard LS, Bagi $P$, Kehlet $H$. Postoperative urinary retention (POUR) in fast-track total hip and knee arthroplasty: A challenge for orthopedic surgeons. Acta Orthop 2014; 85:8-10.

12. Fowler SJ, Symons J, Sabato S, Myles PS. Epidural analgesia compared with peripheral nerve blockade after major knee surgery: a systematic review and meta-analysis of randomized trials. Br J Anaest 2008; 100:154-64.

13. Choi P, Bhandari M, Scott J, Douketis JD. Epidural analgesia for pain relief following hip or knee replacement. Cochrane Database Syst Rev 2003; 3:CD003071.

14. Cook P, Stevens J, Gaudron C. Comparing the effects of femoral nerve block versus femoral and sciatic nerve block on pain and opiate consumption after total knee arthroplasty. J Arthroplasty 2003; 18:583-6.

15. Balderi T, Carli F. Urinary retention after total hip and knee arthroplasty. Minerva Anestesiol 2010; 76:120-30.

16. McQueen DA, Kelley HK, Wright TF. A comparison of epidural and non-epidural anesthesia and analgesia in total hip or knee arthroplasty patients. Orthopedics 1992; 15:169-73.

17. Singelyn FoJ, Ferrant T, Malisse MF, Joris D. Effects of intravenous patient-controlled analgesia with morphine, continuous epidural analgesia, and continuous femoral nerve sheath block on rehabilitation after unilateral total-hip arthroplasty. Reg Anesth Pain Med 2005; 30:452-7.

18. Chan EY, Fransen M, Parker DA, Assam PN, Chua N. Femoral nerve blocks for acute postoperative pain after knee replacement surgery. Cochrane Database Syst Rev. 2014; 5:CD009941.

19. Chu CP, Yap JC, Chen PP, Hung HH. Postoperative outcome in Chinese patients having primary total knee arthroplasty under general anaesthesia/intravenous patient-controlled analgesia compared to spinal-epidural anaesthesia/analgesia. Hong Kong Med J 2006; 12:442-7.

20. Izard JP, Sowery RD, Jaeger MT, Siemens DR. Parameters affecting urologic complications after major joint replacement surgery. Can J Urol 2006; 13:3158-63. 